\title{
Nickel Nanoparticles Exposure and Reproductive Toxicity in Healthy Adult Rats
}

\author{
Lu Kong ${ }^{1}$, Meng Tang ${ }^{1, *}$, Ting Zhang ${ }^{1}$, Dayong Wang ${ }^{2}$, Ke Hu ${ }^{1}$, Weiqi Lu ${ }^{1}$, Chao Wei ${ }^{1}$, \\ Geyu Liang ${ }^{1}$ and Yuepu Pu ${ }^{1, *}$
}

1 Key Laboratory of Environmental Medicine Engineering, Ministry of Education, School of Public Health, Southeast University, Nanjing 210009, China; E-Mails: konglu@seu.edu.cn (L.K.); zhangting1207@gmail.com (T.Z.); 18051969217@163.com (K.H.); starvich@126.com (W.L.); seuweichao@163.com (C.W.); gyliang@seu.edu.cn (G.L.)

2 Key Laboratory of Developmental Genes and Human Disease in Ministry of Education, Medical School of Southeast University, Nanjing 210009, China; E-Mail: dayongw@seu.edu.cn

* Authors to whom correspondence should be addressed;

E-Mails: tm@seu.edu.cn (M.T.); 101010433@seu.edu.cn (Y.P.);

Tel.: +86-25-8327-2564 (M.T.); +86-25-8327-2565 (Y.P.).

External Editor: Bing Yan

Received: 4 September 2014; in revised form: 5 November 2014 / Accepted: 10 November 2014 / Published: 17 November 2014

\begin{abstract}
Nickel is associated with reproductive toxicity. However, the reproductive toxicity of nickel nanoparticles (Ni NPs) is unclear. Our goal was to determine the association between nickel nanoparticle exposure and reproductive toxicity. According to the one-generation reproductive toxicity standard, rats were exposed to nickel nanoparticles by gavage and we selected indicators including sex hormone levels, sperm motility, histopathology, and reproductive outcome etc. Experimental results showed nickel nanoparticles increased follicle stimulating hormone (FSH) and luteinizing hormone ( $\mathrm{LH}$ ), and lowered etradiol $\left(E_{2}\right)$ serum levels at a dose of 15 and $45 \mathrm{mg} / \mathrm{kg}$ in female rats. Ovarian lymphocytosis, vascular dilatation and congestion, inflammatory cell infiltration, and increase in apoptotic cells were found in ovary tissues in exposure groups. For male rats, the weights decreased gradually, the ratio of epididymis weight over body weight increased, the motility of rat sperm changed, and the levels of FSH and testosterone (T) diminished. Pathological results showed the shedding of epithelial cells of raw seminiferous tubule, disordered arrangement of cells in the tube, and the appearance of cell
\end{abstract}


apoptosis and death in the exposure group. At the same time, Ni NPs resulted in a change of the reproductive index and the offspring development of rats. Further research is needed to elucidate exposure to human populations and mechanism of actions.

Keywords: nickel nanoparticle; reproductive toxicity; one-generation; rats

\section{Introduction}

Nickel is a silver-white metallic chemical element that is naturally present in the Earth's crust [1]. Because of its unique physical and chemical properties, being tough, harder than iron, ferromagnetic, having good plasticity and highly resistant to rusting and corrosion, nickel and its compounds are widely used in industry [2]. Nickel is an essential element for at least several animal species. These animal studies associate nickel deprivation with depressed growth, reduced reproductive rates, and alterations of serum lipids and glucose [3].

Nickel is known as a potentially harmful element for humans. Its concentration in the environment can rise due to industrial activities [4-10]. Human exposure to nickel or its compounds has the potential to produce a variety of pathological effects, which may include cutaneous inflammations such as swelling, reddening, eczema and itching on skins, and may also include allergy reactions and teratogenicity in the human body. The most important adverse health effects due to nickel exposure are lung fibrosis and lung cancer [10,11]. Epidemiological studies have indicated that occupational exposure to nickel increased the incidence of some human cancers, such as lung, head, neck and nasal cancers, and so forth [12-26]. Nickel compounds have long been classified as human carcinogens according to the International Agency for Research on Cancer [27,28]. Furthermore, excessive nickel micro-particles (Ni MPs) can induce reproductive toxicity. Nickel ions exert a wide variety of adverse effects on reproduction and development, including influence on male and female subfertility or fertility, abortions, malformations and birth defects [29-31]. For example, Ni MPs treatment can decrease the reproductive capacity of zebra-fish and the reproduction success of the $S$. litura Noctuid moth $[4,32]$. Soluble nickel salts have been demonstrated to disturb mammalians and model organism reproductive functions $[33,34]$. Hormonal effects may play an important role in the reproductive toxicology of nickel both at the neuroendocrine and gonadal levels in the hypothalamic-pituitary-gonadal (HPG) axis [33].

With the rapid development of nanotechnology, the application of nanomaterials is becoming more and more extensive. Manufactured nanomaterials, defined as materials with at least one dimension ranging from 1 to $100 \mathrm{~nm}$, possess unique or even increased physicochemical properties, such as nanoscale size effects, quantum effects, expanded surface area as well as unique electric, thermal, mechanical, and imaging properties. These special characteristics show promise for nanomaterials to be used in a wide range of applications [35]. At present, nanomaterials are beginning to influence human life in many ways, therefore understanding the environmental health and safety aspect of nanoparticles has become a crucial problem [36]. Metallic nanoparticles including metallic nickel nanoparticles (Ni NPs) are among the most widely used types of nanomaterials [37]. Ni NPs give a product with many new characteristics, including a high level of surface energy, high magnetism, low melting point, high surface area, and low burning point. Ni NPs are used in many fields, such as 
for catalysts, for magnetic materials, in biological medicine and for conductive paste etc. So human and environmental exposures to Ni NPs become inevitable, but health and environmental impacts have not been fully investigated. According to some studies, Ni NPs may induce liver and spleen injury, lung inflammation, cardiac toxicity [38], and exhibit higher carcinogenic potential than fine particles [39]. As mentioned before, Ni MPs have been shown to have reproductive toxicity, and Ni NPs may also induce reproductive toxicity [40]. However, there is still a gap in the evaluation of their reproductive toxicity. The goal of the present study was to evaluate the reproductive toxicity of Ni NPs to rats.

\section{Results}

\subsection{Characterization of Ni NPS}

The SEM and TEM images showed that Ni NPs were spherical in shape. The size distribution varied from 30 to $100 \mathrm{~nm}$ in diameter, the average size of Ni NPs was $90 \mathrm{~nm}$, and there was slight agglomeration. In the dispersion, the particle size of Ni NPs of $5 \mu \mathrm{g} / \mathrm{mL}$ had a distribution from 260 to $725 \mathrm{~nm}$, and peak size was about $444 \mathrm{~nm}$. However, the average particle size of $12.5 \mu \mathrm{g} / \mathrm{mL}$ had a distribution from 400 to $879 \mathrm{~nm}$, and peak size of about $522 \mathrm{~nm}$. See Figure 1. Meanwhile the average size distribution of Ni MPs is $3.34 \pm 0.67 \mu \mathrm{m}$ without agglomeration.

Figure 1. SEM (scale bar $=200 \mathrm{~nm})(\mathbf{a})$ and TEM (scale bar $=100 \mathrm{~nm})(\mathbf{b})$ images and particle size distributions of nickel nanoparticles (Ni NPs) of $5 \mu \mathrm{g} / \mathrm{mL}$ (c) and $12.5 \mu \mathrm{g} / \mathrm{mL}$ (d).

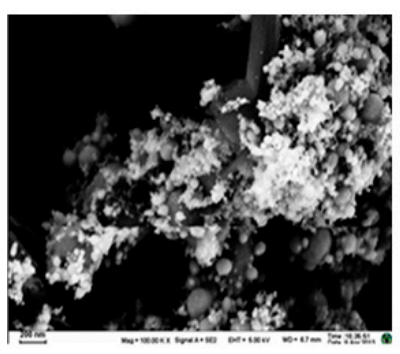

(a)

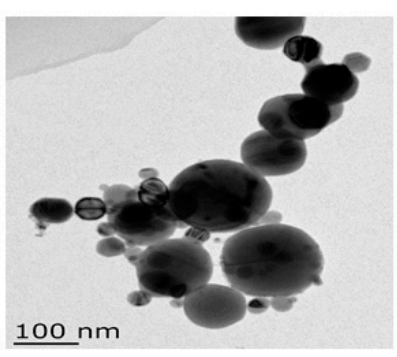

(b)

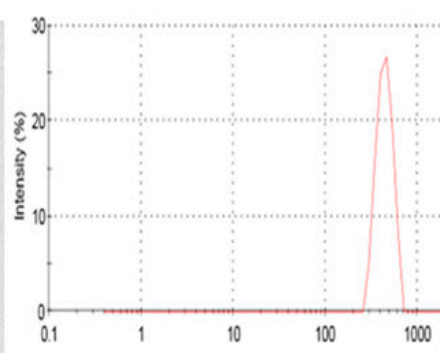

(c)

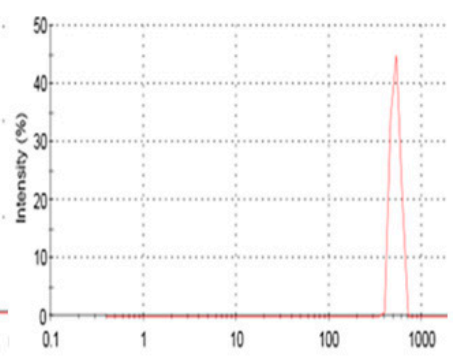

(d)

\subsection{Body Weights and Organ Weight Coefficients}

No female or male deaths occurred during the study and clinical observations did not show any significant findings. Data for female and male rat body weight gain and organ weight coefficients appear in Table 1. No statistically significant difference was found in female body weights and coefficients of liver, kidney, and ovary between the control and Ni NPs-exposed groups. However the mean body weight of Ni MPs at week 13 decreased significantly from controls. The ratio of lung weight over body weight of female rats increased gradually on increasing the dose of Ni NPs. Furthermore, lung weight coefficients for female rats treated with Ni MPs increased significantly compared to control and the high dose of Ni NPs. For male rats, initial weights of different groups had no difference significantly. The differences in body weight at the first week to the final week of the experimental treatments were large, and compared with the control group, the body weights of the high dose group and Ni MPs increased significantly. At the same time, the experiments showed organ weight coefficients of lung, testis, and epididymis increased significantly when treated with high dose 
Ni NPs and Ni MPs compared with the control. Moreover, lung coefficients for male rats treated with Ni MPs increased significantly compared with the high dose of Ni NPs.

Table 1. Mean body weight and organ weight coefficients for female and male rats.

\begin{tabular}{cccccc}
\hline Group & Control & Low Dose & Mid Dose & High Dose & Ni MPs \\
\hline \multicolumn{5}{c}{ Female parental rats } \\
& \multicolumn{5}{c}{ Mean body weight (g) } \\
\hline zero week & $91 \pm 6$ & $93 \pm 7.20$ & $93 \pm 7$ & $93 \pm 7$ & $92 \pm 6$ \\
first week & $160 \pm 16$ & $165 \pm 17$ & $166 \pm 8$ & $161 \pm 20$ & $160 \pm 15$ \\
fourth week & $235 \pm 17$ & $234 \pm 24$ & $233 \pm 15$ & $231 \pm 26$ & $229 \pm 19$ \\
seventh week & $269 \pm 19$ & $276 \pm 26$ & $277 \pm 19$ & $271 \pm 25$ & $267 \pm 22$ \\
tenth week & $329 \pm 26$ & $333 \pm 34$ & $336 \pm 22$ & $324 \pm 28$ & $313 \pm 29$ \\
thirteenth week & $355 \pm 43$ & $359 \pm 49$ & $340 \pm 23$ & $337 \pm 33$ & $326 \pm 30 *$ \\
sixteenth week & $322 \pm 31$ & $337 \pm 40$ & $325 \pm 20$ & $322 \pm 34$ & $316 \pm 28$ \\
final weight & $307 \pm 28$ & $313 \pm 29$ & $314 \pm 21$ & $307 \pm 28$ & $300 \pm 24$ \\
\hline \multicolumn{5}{c}{ Organ weight coefficient $(\%)$} \\
\hline liver & $2.84 \pm 0.55$ & $2.94 \pm 0.52$ & $2.65 \pm 0.32$ & $2.90 \pm 0.49$ & $2.76 \pm 0.41$ \\
kidney & $0.65 \pm 0.06$ & $0.65 \pm 0.06$ & $0.63 \pm 0.05$ & $0.65 \pm 0.05$ & $0.64 \pm 0.06$ \\
lung & $0.50 \pm 0.07$ & $0.51 \pm 0.08$ & $0.53 \pm 0.08$ & $0.53 \pm 0.09^{1}$ & $0.61 \pm 0.13 *$ \\
ovary & $0.05 \pm 0.01$ & $0.05 \pm 0.01$ & $0.05 \pm 0.01$ & $0.05 \pm 0.01$ & $0.05 \pm 0.01$ \\
\hline
\end{tabular}

Male parental rats

Mean body weight $(\mathrm{g})$

\begin{tabular}{cccccc}
\hline zero week & $100 \pm 7$ & $98 \pm 9$ & $99 \pm 7$ & $99 \pm 10$ & $100 \pm 8$ \\
first week & $196 \pm 12$ & $196 \pm 13$ & $195 \pm 13$ & $185 \pm 18$ & $182 \pm 11^{*}$ \\
third week & $303 \pm 14$ & $301 \pm 17$ & $293 \pm 21$ & $284 \pm 13^{*}$ & $284 \pm 13 *$ \\
fifth week & $370 \pm 13$ & $376 \pm 22$ & $365 \pm 23$ & $357 \pm 16$ & $345 \pm 25^{*}$ \\
seventh week & $421 \pm 18$ & $419 \pm 17$ & $408 \pm 23$ & $401 \pm 17 *$ & $388 \pm 21^{*}$ \\
ninth week & $453 \pm 20$ & $459 \pm 24$ & $453 \pm 23$ & $434 \pm 19 *$ & $432 \pm 23^{*}$ \\
eleventh week & $487 \pm 22$ & $486 \pm 22$ & $477 \pm 20$ & $460 \pm 18^{*}$ & $457 \pm 28^{*}$ \\
\hline \multicolumn{5}{c}{ Organ weight coefficient (\%) } \\
\hline liver & $2.13 \pm 0.12$ & $2.13 \pm 0.12$ & $2.14 \pm 0.14$ & $2.16 \pm 0.13$ & $2.16 \pm 0.15$ \\
kidney & $0.60 \pm 0.05$ & $0.60 \pm 0.04$ & $0.61 \pm 0.03$ & $0.60 \pm 0.03$ & $0.61 \pm 0.04$ \\
lung & $0.35 \pm 0.04$ & $0.37 \pm 0.05$ & $0.41 \pm 0.05 *$ & $0.43 \pm 0.077^{1}$ & $0.57 \pm 0.12 *$ \\
testis & $0.61 \pm 0.04$ & $0.63 \pm 0.05$ & $0.65 \pm 0.04$ & $0.64 \pm 0.03 *$ & $0.67 \pm 0.06 *$ \\
epididymis & $0.19 \pm 0.06$ & $0.23 \pm 0.01$ & $0.23 \pm 0.02 *$ & $0.25 \pm 0.02 *$ & $0.23 \pm 0.03$ \\
\hline
\end{tabular}

$* p<0.05$, compared with control group $(0 \mathrm{mg} / \mathrm{kg}$ body weight $(\mathrm{BW})) ;{ }^{1} p<0.05$, compared with Ni MPs $(45 \mathrm{mg} / \mathrm{kg} \mathrm{BW})$.

\subsection{Sperm Motility of Parental Males}

After 15 and $45 \mathrm{mg} / \mathrm{kg} /$ day $\mathrm{Ni}$ NPs exposures, linearity (LIN) decreased significantly, and curvilinear velocity (VCL) of the high dose group decreased significantly compared with control. However, the motility test of rat sperm showed Ni NPs induced the increase of beat cross frequency (BCF). At the same time, Ni MPs exposure decreased the motility of the parameters LIN and VCL, and increased BCF significantly. See Table 2. 
Table 2. Effects of nickel nanoparticles (Ni NPs) on rat sperm motility.

\begin{tabular}{cccccc}
\hline Group & Control & Low Dose & Mid Dose & High Dose & Ni MPs \\
\hline average path velocity $(\mathrm{VAP})(\mu \mathrm{m} / \mathrm{s})$ & $210 \pm 15$ & $211 \pm 14$ & $209 \pm 10$ & $207 \pm 8$ & $204 \pm 8$ \\
curvilinear velocity $(\mathrm{VCL})(\mu \mathrm{m} / \mathrm{s})$ & $410 \pm 24$ & $405 \pm 25$ & $398 \pm 18$ & $382 \pm 21 *$ & $384 \pm 29 *$ \\
straight line velocity (VSL) $(\mu \mathrm{m} / \mathrm{s})$ & $145 \pm 9$ & $144 \pm 9$ & $144 \pm 6$ & $141 \pm 6$ & $140 \pm 8$ \\
beat cross frequency (BCF) $(\mathrm{Hz})$ & $19 \pm 1$ & $20 \pm 1 *$ & $20 \pm 1 *$ & $20 \pm 1 *$ & $20 \pm 1 *$ \\
$\quad$ straightness (STR) (\%) & $67 \pm 1$ & $68 \pm 1$ & $68 \pm 1$ & $67 \pm 1$ & $67 \pm 1$ \\
$\quad \begin{array}{l}\text { linearity (LIN) (\%) } \\
\text { amplitude of lateral head }\end{array}$ & $37 \pm 1$ & $37 \pm 1$ & $36 \pm 1 *$ & $36 \pm 1 *$ & $36 \pm 1 *$ \\
displacement (ALH) $(\mu \mathrm{m})$ & $18 \pm 1$ & $18 \pm 0$ & $19 \pm 1$ & $19 \pm 1$ & $19 \pm 1$ \\
elongation (ELON) $(\%)$ & $68 \pm 1$ & $69 \pm 1$ & $68 \pm 2$ & $68 \pm 1$ & $68 \pm 2$ \\
\hline
\end{tabular}

$* p<0.05$, compared with control group.

\subsection{Effect of Ni NPs on Serum Hormone Concentrations}

To determine whether Ni NPs exposure induces alterations to the female or male reproductive system, according to the one-generation reproductive toxicity study, we treated adult female Sprague-Dawley rats with Ni NPs at $5 \mathrm{mg} / \mathrm{kg} \mathrm{BW}$ (low dose), $15 \mathrm{mg} / \mathrm{kg} \mathrm{BW}$ (mid-dose), and $45 \mathrm{mg} / \mathrm{kg} \mathrm{BW}$ (high dose) for eighteen weeks by gavage. Similarly we treated male rats with Ni NPs for ten weeks. Mid-dose and high dose of Ni NPs significantly increased serum FSH concentrations in female rats compared with controls (Figure 2A), and all doses of Ni NPs significantly increased LH in female rats (Figure 2B). However, high dose of Ni NPs significantly increased serum FSH and LH concentrations compared to Ni MPs (Figure 2A,B). In contrast, the serum $\mathrm{E}_{2}$ of the females was decreased by Ni NPs exposure (Figure 2C). Exposure to Ni NPs (mid-dose and high-dose) resulted in the same alteration of serum FSH and $\mathrm{T}$ concentrations in male rats as observed with Ni MPs (Figure 2D,F). Compared with Ni MPs, the levels of FSH and T in serum were significantly lower while the level of LH was significantly higher in the high dose of Ni NPs (Figure 2D-F).

\subsection{Histopathology}

To confirm whether Ni NPs treatment may damage the reproductive system of rats, and change serum hormone levels (FSH, LH, $\mathrm{E}_{2}$ and $\mathrm{T}$ ) caused by ovary and testis tissues damages, we examined the histopathology of ovaries and testes of parental rats. There were no adverse histopathological presentations observed in the control group (Figure 3A). However, pathological results showed vascular dilatation and congestion (Figure 3B,C), ovarian lymphocytosis (Figure 3D), luteal cells increasing and becoming cavitated (Figure 3E), increased eosinophils and inflammatory cell infiltration (Figure 3F) in rat ovaries tissue in the Ni NPs exposure group. At the same time, a histologic section of testis tissue showed seminiferous tubules lined by germ cells in various stages of development (the spermatogenic series), and containing luminal spermatozoa in the control group (Figure 4A), with the shedding of epithelial cells of the raw seminiferous tubule (Figure 4B), disorder arrangement of cells in the tube (Figure 4C), and appearance of cell apoptosis and death (Figure 4D) in the Ni NPs or Ni MPs group. 
Figure 2. Effects of Ni NPs on serum hormone concentrations in rats. Follicle stimulating hormone (FSH) in females (A); Luteinizing hormone (LH) in females (B); Estradiol ( $\left.\mathrm{E}_{2}\right)$ in females $(\mathbf{C})$; FSH in males (D); LH in males $(\mathbf{E})$; Testosterone $(\mathrm{T})$ in males $(\mathbf{F})$. Serum hormone concentrations were measured by ELISA. Values represent the mean $\pm \mathrm{SD}$ $(n=7) .{ }^{*} p<0.05$, compared with control group $(0 \mathrm{mg} / \mathrm{kg} \mathrm{BW}) ;{ }^{1} p<0.05$, compared with Ni MPs (45 mg/kg BW).
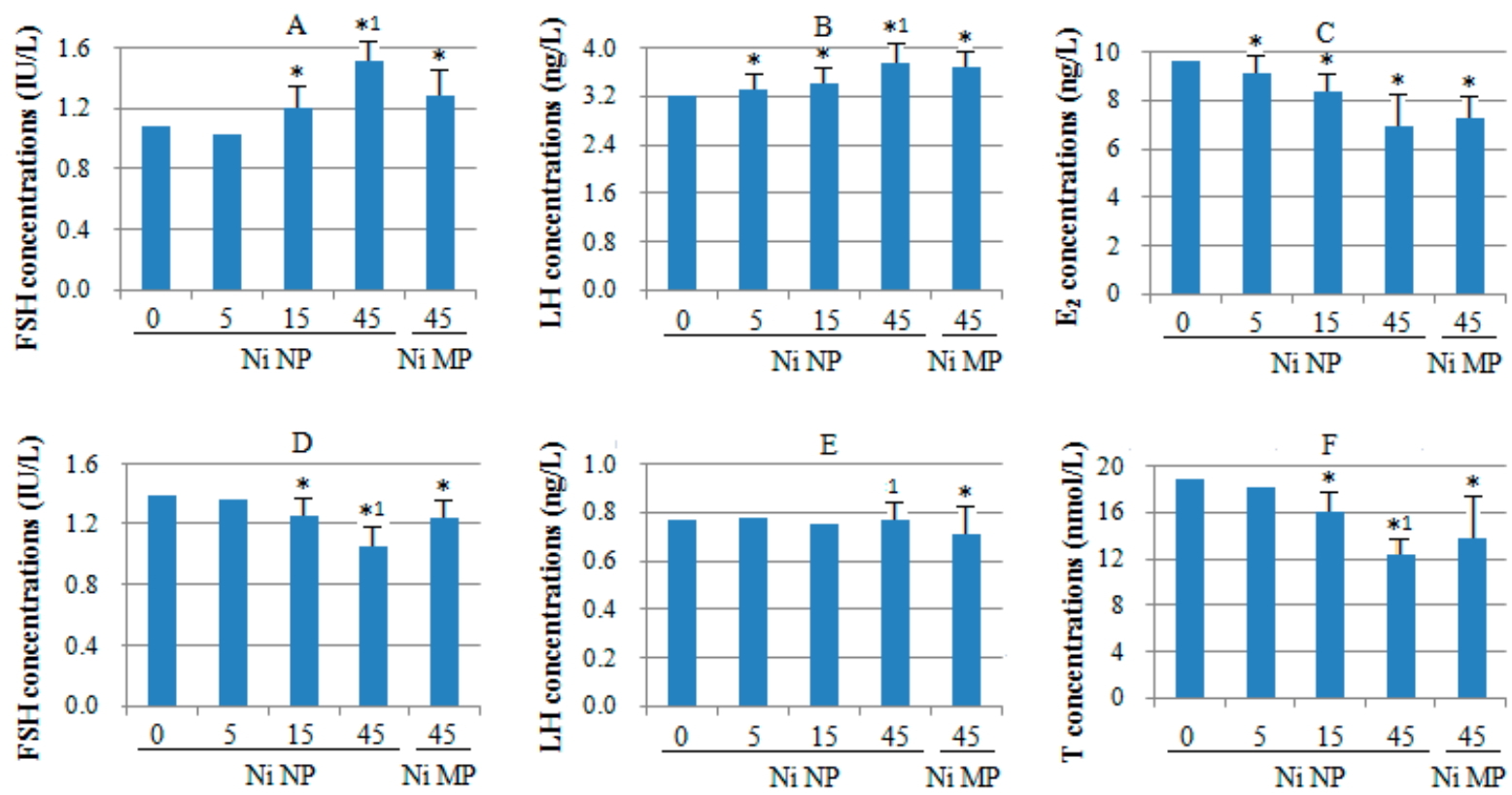

Figure 3. Effects of Ni NPs on histopathology of ovaries in female rats. The control group (A); $15 \mathrm{mg} / \mathrm{kg} \mathrm{BW}$ (B); $45 \mathrm{mg} / \mathrm{kg}$ (C-E); Ni MPs group (F). Original magnification was 100×, $200 \times$ and $400 \times(100 \times$ refers to picture A, B and $\mathbf{C} ; 200 \times$ refers to picture $\mathbf{D}$ and $\mathbf{E} ; 400 \times$ refers to picture $\mathbf{F})$. The arrow on $(\mathbf{B})$ and $(\mathbf{C})$ points to vascular dilatation and congestion, on (D) it points to Lymphocytes, on (E) it points to luteal cells, and on (F) it points to eosinophils and inflammatory cells.

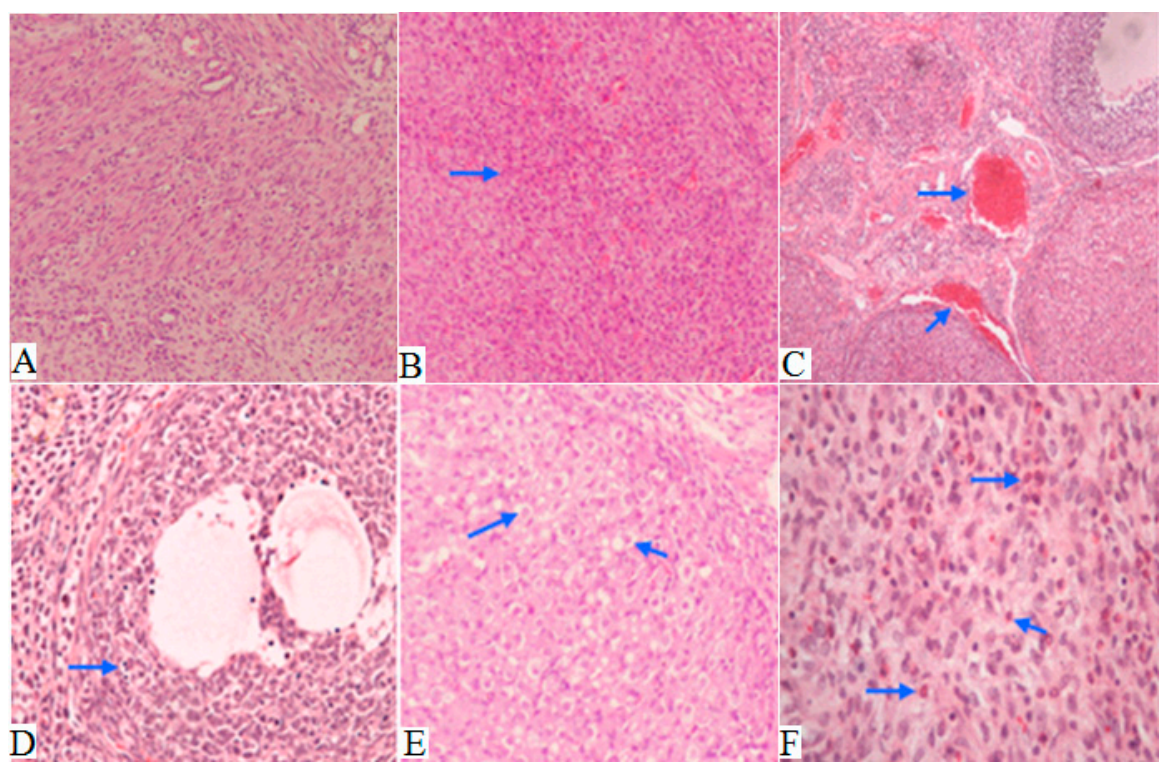


Figure 4. The testicular histopathological changes of the male rats. The control group (A); $45 \mathrm{mg} / \mathrm{kg} \mathrm{BW}$ (B-D). Original magnification $200 \times$ and $400 \times(200 \times$ refers to picture A, B and $\mathbf{C} ; 400 \times$ refers to picture $\mathbf{D})$. The arrow on $(\mathbf{C})$ points to disordered arrangement of cells in the tube and on (D) it points to cell apoptosis.

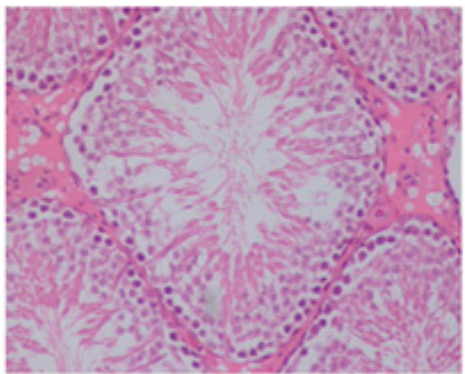

(A)

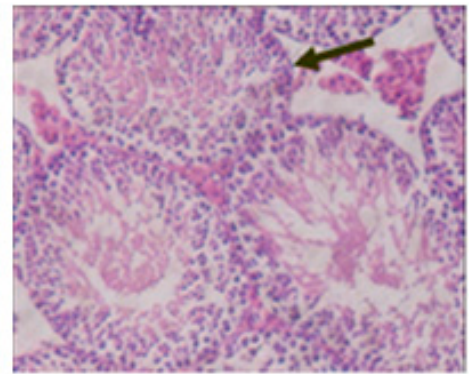

(C)

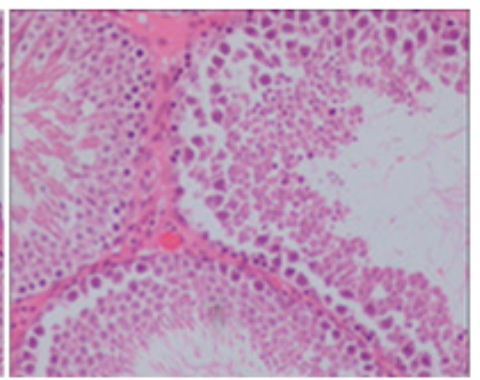

(B)

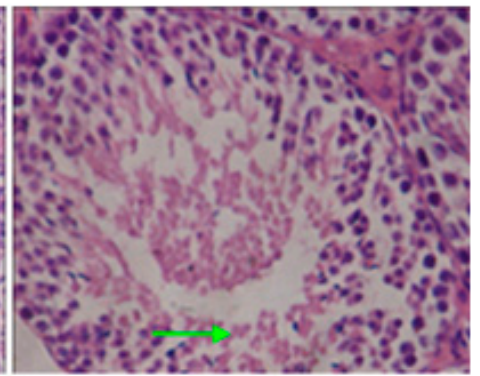

(D)

\subsection{Reproductive Outcome}

The effect of Ni NPs on reproductive index and offspring development of rats was studied. (See Tables 3 and 4). The results demonstrated that birth survival rate in fetal rats to parents with Ni NPs and Ni MPs significantly decreased compared with fetal rats of parents without Ni NPs or Ni MPs (control), and the birth survival rate of the high dose of Ni NPs significantly decreased compared with Ni MPs. At the same time, the feeding survival rates in the Ni NPs and Ni MPs groups were also lower than the control group. However, the feeding survival rate of the high dose Ni NPs was higher than that of Ni MPs. Out of 104 live born rats 67 survived (64.4\%) after 21 days at a high dose of Ni NPs and out of 174 live born rats 75 survived (43.1\%) after weaning (21 days) in Ni MPs. Ni NPs could also reduce the chance of mating success and pregnancy in rats, but there was no statistical significance $(p>0.05)$. Ni NPs caused weight gain loss in the neonatal rats at $4,7,14$, and 21 days of age (Table 4). The offspring weights of mid-dose and high dose of Ni NPs and Ni MPs significantly decreased compared with the control group. However, there was no statistical significance between high dose of Ni NPs and Ni MPs. 
Table 3. Effects of Ni NPs on the rats reproductive index (\%).

\begin{tabular}{cccccc}
\hline Group & $\begin{array}{c}\text { Mating } \\
\text { Success Rate }\end{array}$ & $\begin{array}{c}\text { Pregnancy } \\
\text { Rate }\end{array}$ & $\begin{array}{c}\text { Live Birth } \\
\text { Rate }\end{array}$ & $\begin{array}{c}\text { Birth Survival } \\
\text { Rate }\end{array}$ & $\begin{array}{c}\text { Feeding } \\
\text { Survival Rate }\end{array}$ \\
\hline control & $100(20 / 20)$ & $100(20 / 20)$ & $100(20 / 20)$ & $94(185 / 196)$ & $79(147 / 185)$ \\
low dose & $90(18 / 20)$ & $90(18 / 20)$ & $100(18 / 18)$ & $86(171 / 198) *$ & $73(125 / 171)$ \\
mid dose & $80(16 / 20)$ & $80(16 / 20)$ & $100(16 / 16)$ & $75(142 / 190) *$ & $65(93 / 142) *$ \\
high dose & $80(16 / 20)$ & $80(16 / 20)$ & $100(16 / 16)$ & $67(104 / 156) *, 1$ & $64(67 / 104) * 1$ \\
Ni MPs & $90(18 / 20)$ & $90(18 / 20)$ & $100(18 / 18)$ & $82(174 / 211) *$ & $43(75 / 174) *$ \\
\hline \multicolumn{6}{c}{$* p<0.05$, compared with control group; ${ }^{1} p<0.05$, compared with Ni MPs $(45 \mathrm{mg} / \mathrm{kg} \mathrm{BW})}$.
\end{tabular}

Table 4. Body weight changes of pup rats during the experiment $(\mathrm{g})$.

\begin{tabular}{cccccc}
\hline Group & Birthday & The 4th Day & The 7th Day & The 14th Day & The 21th Day \\
\hline Control & $7 \pm 1$ & $11 \pm 2$ & $16 \pm 3$ & $31 \pm 3$ & $50 \pm 5$ \\
Low dose & $7 \pm 1$ & $10 \pm 2 *$ & $15 \pm 3$ & $27 \pm 5 *$ & $48 \pm 5$ \\
Mid dose & $7 \pm 0$ & $10 \pm 2 *$ & $14 \pm 3 *$ & $25 \pm 7 *$ & $46 \pm 6 *$ \\
High dose & $7 \pm 0$ & $10 \pm 2$ & $14 \pm 2$ & $24 \pm 2 *$ & $42 \pm 6 *$ \\
Ni MPs & $7 \pm 0$ & $9 \pm 2 *$ & $13 \pm 3 *$ & $26 \pm 2 *$ & $45 \pm 7 *$ \\
\hline
\end{tabular}

$* p<0.05$, compared with control group.

\section{Discussion}

Nanomaterials, such as gold, silver, and gold-silver alloy nanoparticles were shown to have reproductive toxicity by impairing key sperm functions, somatic and reproductive cells, and mammalian gametes [41-43]. The results of the current study demonstrate the effects on male and female rat reproductive performance following Ni NPs treatments during mating, gestation, and lactation. Additionally, the exposure to Ni NPs adversely affected pup survival or development.

It is well known that body weight and organ weight coefficients are sensitive indicators of potentially toxic chemicals in general toxicity studies [44,45]. As described, repeated gavage administration of Ni NPs to rats caused a significant suppression in body weight gain in the male $45 \mathrm{mg} / \mathrm{kg}$ group.

At the same time, the decreased ovary weight coefficients and increased testis weight coefficients observed in the Ni NPs and Ni MPs groups are closely related to the treatment of Ni NPs, since correlated histopathological changes such as vascular dilatation and congestion, ovarian lymphocytosis, luteal cells increasing and becoming cavitation, increased eosinophils and inflammatory cell infiltration in female ovary tissues, the shedding of epithelial cells of the raw seminiferous tubule, disordered arrangement of cells in the tube, and appearance of cell apoptosis and death in male testis tissue, were detected on exposure of Ni NPs groups. This interpretation was also supported by the work of Feron in that a changed organ weight coefficient should be considered to be due to an effect of chemicals (i.e., Ni NPs) in cases of growth reduction and organ damage [46]. Although the difference between the groups was not statistically significant in female rats, an increase in lung weight coefficient observed in the male 15 and $45 \mathrm{mg} / \mathrm{kg}$ groups was considered to be an adverse effect of the Ni NPs treatment test. This finding suggests that the lung was one of the major targets of Ni NPs in rats. 
It is well noted that individual susceptibility to chemical toxicity may be influenced by gender, and differences in physical constitution and physiology may also play a major role in determining gender-specific response and toxicity $[47,48]$. In the present study, the Ni NPs-related adverse effects on body weight and organ weight coefficients were slightly greater in males than in females perhaps due to lower body fat. Although the exact cause of the gender difference is unknown, the present detailed data on toxicokinetics and metabolism of the test chemicals can provide good information in determining the gender-specific toxicity of Ni NPs.

The hypothalamic-pituitary-gonadal (HPG) axis is the hormone system whereby the hypothalamus secretes so-called releasing hormones, which are transported via the blood to the pituitary gland. There, the releasing hormones induce the production and secretion of gonadotropins (i.e., LH and FSH), which in turn are transported by the blood to the gonads (i.e., the ovaries and testes). Generally speaking, in females, LH and FSH stimulate the ovarian follicle that contains the maturing egg to produce estradiol. After ovulation has occurred, $\mathrm{LH}$ also promotes production of progesterone and $\mathrm{E}_{2}$ by the corpus luteum. Both hormones participate in a negative feedback mechanism through most of the menstrual cycle, suppressing GnRH release from the hypothalamus and LH release from the pituitary $[49,50]$. The mechanism also applies to rat estrous cycles. In males, LH stimulates certain cells in the testes (e.g., Leydig cells) to release T. FSH and T are key regulators of another set of testicular cells (e.g., Sertoli cells), which support and nourish the sperm cells during their maturation. The HPG axis in the male is regulated through a variety of factors [51,52]. For example, $\mathrm{T}$ is part of a negative feedback mechanism that inhibits GnRH release by the hypothalamus and LH release by the pituitary. (See Figure 5). Exogenous chemicals can interfere with the normal functioning of the HPG axis, resulting in reduced fertility or even infertility in both females and males. Here we describe the effects of Ni NPs on aspects of serum sex hormone levels (i.e., FSH, LH, $\mathrm{E}_{2}$ or T) in female and male rats. The results of the current study demonstrate Ni NPs increased the level of serum FSH and LH, and decreased $\mathrm{E}_{2}$ associated with significant and dose-dependent in females. Our results indicate the effects of Ni NPs on the female rat ovarian reserve. It is probably an indication of the decreased level of serum $\mathrm{E}_{2}$ and ovarian hormone secretion following ovarian damage with Ni NPs, which increased the level of serum FSH and LH by negative feedback. Meanwhile, the male rat serum FSH, LH and T content analysis showed the levels of FSH and T were decreased significantly by Ni NPs treatment. The results suggest that the decreased level of $\mathrm{T}$, which resulting from testicular damage, affected testicular spermatogenesis. Testicular damage was exacerbated by reduced FSH. From the T value trends, $\mathrm{T}$ values reflect the extent of spermatogenic cell damage, and spermatogenesis. The effect of $\mathrm{Ni}$ NPs on testicular function in male rats was severe with lowered levels of T. The effects of the Ni MPs on serum sex homone levels are similar to the effects of Ni NPs, but to a lower extent. The change of hormone reproductive levels indicates the abnormal reproductive axis function, which correlated male and female infertility [53]. The current results showed Ni NPs had reproductive toxicity by affecting hormone levels between male and female rats. 
Figure 5. Schematic representation of the hypothalamic-pituitary-gonadal (HPG) axes.
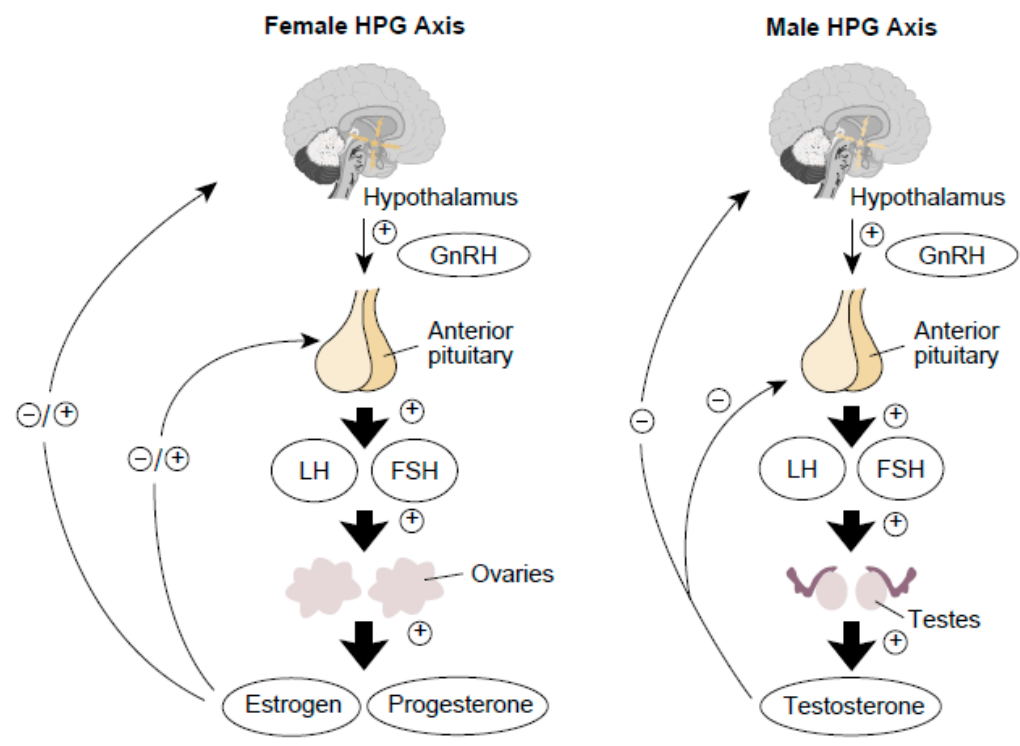

Sperm motility can indirectly reflect its fertilizability. There are correlations between fertility rate and motility parameters in vitro fertilizing capacity of rat spermatozoa [54]. CASA provides the means for an objective classification of sperm motility. Using digital images of each sperm track, CASA machines are able to analyze, by processing algorithms, the motion properties of spermatozoa. The commonly reported CASA parameters include VCL, VAP, VSL, BCF, ALH, LIN, STR and ELON. These CASA parameters have been modelled and refined mathematically to describe best the motion parameters of each spermatozoon as it travels through a microscopic field $[55,56]$. The study showed that VCL, LIN and BCF were the most sensitive indicators of male reproductive toxicity, while STR and ELON appeared less sensitive. In this study, it was found that Ni NPs exerted adverse effects on the sperm motility in a dose-dependent manner. The values of VCL and LIN were progressively reduced with increasing exposure dose of Ni NPs. Furthermore, we observed an increase of BCF due to Ni NPs treatment. The data were consistent with our study of histopathology. $\mathrm{BCF}$, along with LIN and VCL, are indicative parameters of spermatic vigor. Observed changes for these parameters in capacitating conditions in vitro could be related to sperm hyperactivation that occurs in vivo and favors the penetration of oocyte. This may be attributed to diminished fertility of Ni NPs in male. In this study, Ni NPs and Ni MPs were found to exert similar effects on sperm motility, which may be to do with their similar molecular structures. Our results are consistent with the conclusions of Sleiman's research about Ag NPs which showed Ag NPs had adverse effects on reproductive functions by affecting sperm quality and quantity, and hormone levels etc.

In the F0 generation, live birth rate was unaffected by Ni NPs treatment, and mating success rate and pregnancy rate were decreased compared to the control group, but were not significantly different. Additionally, grossly malformed pups were not observed in any groups. However, in the F1 generation, birth survival rate and feeding survival rate were decreased significantly. Ni NPs and Ni MPs caused the loss of neonatal rat weight gain on some days compared with the control group. The possible reason is that the important function of the genes of rat mammary development and lactation was affected by Ni particles resulting in the lower lactation capacity. So the neonatal rats cannot get enough nutrition for their growth and development. 


\section{Experimental Section}

\subsection{Materials, Preparation and Characterization}

\subsubsection{Materials of Ni NPs and Ni MPs}

Ni NPs, average size $90 \mathrm{~nm}$ (Product Code: FNiN-80; Black Powder, Purity: 99\%, Surface area $\geq 8 \mathrm{~m}^{2} / \mathrm{g}$, Bulk density: $0.06-0.8 \mathrm{~g} / \mathrm{cm}^{3}$ ) were purchased from Nano Science and Technology Co., Ltd., Kunshan-miyou, Kunshan, China. Ni MPs, average size of $3 \mu \mathrm{m}$ (Product Code: ST-M-008-2; Gray-black powder, Purity: $99.0 \%$, Surface area $\geq 3 \mathrm{~m}^{2} / \mathrm{g}$ ) were purchased from Material Technology Co., Ltd. of Shanghai, China.

\subsubsection{Preparation of Ni NPs and Ni MPs}

Stock suspensions of Ni NPs and Ni MPs were prepared in normal saline $(10 \mathrm{mg} / \mathrm{mL})$ by sonication for 30 seconds on ice using a sonifier (Misonix Incorporation, New York, NY, USA). The particle suspensions were kept on ice for $30 \mathrm{~s}$ and sonicated again for a total of $3 \mathrm{~min}$ at a power of $400 \mathrm{~W}$. Before use, Ni NPs and Ni MPs were diluted to the desired concentrations with $0.9 \%$ sodium chloride solution. All samples were prepared under sterile conditions.

\subsubsection{Characterization of Ni NPs}

The physical properties of Ni NPs were characterized by scanning electron microscope (SEM, JEOL Ltd., Tokyo, Japan) and transmission electron microscopy (TEM, JEOL Ltd., Tokyo, Japan). Then the water-dispersibility and agglomeration state of Ni NPs were studied in normal saline by Zetaszier Nano-ZS (Malvern Instruments Ltd., Malvern, UK).

\subsection{One-Generation Reproductive Toxicity Test}

Male and female Sprague-Dawley rats of 80-100 g were purchased from Shanghai Super-B\&K laboratory animal Corp. Ltd. (Shanghai, China) and housed under controlled environment $\left(22 \pm 2{ }^{\circ} \mathrm{C}\right.$, $12 \mathrm{~h}$ light/dark cycle, free access to food and water) in the Experimental Animal Center, Southeast University (Nanjing, China). The animal approval number was SCXK 2008-0016. All the animal experiments were performed in compliance with the local ethics committee. Animal care and use were in accordance with China's Guidelines for Care and Use of Laboratory Animals (National Research Council, 1996).

This study was conducted in compliance with OECD guideline test 415: One-Generation Reproduction Toxicity Study. The 50 male and 100 female rats were divided into five groups including control group, Ni NPs (90 nm) groups (high dose 45, mid-dose 15 and low dose $5 \mathrm{mg} / \mathrm{kg} / \mathrm{day}$, respectively) and Ni MPs $(3 \mu \mathrm{m})$ group $(45 \mathrm{mg} / \mathrm{kg} / \mathrm{day})$ in such a way as to equalize group means and standard deviations of body weights. Each group consisted of 10 males and 20 females, as F0 parental rats. Both male and female F0 parental rats were administered by gavage with different doses of Ni NPs, Ni MPs and $0.9 \%$ sodium chloride solution (control group) for 10 weeks before the initiation of the mating period. Females continued to receive test samples during gestation and lactation. 
At the end of ten weeks of exposure, the F0 rats were mated on the basis of one male to two females, selected randomly within each dose group for a period of 14 days. The observation of a vaginal plug in a vaginal smear was considered evidence of successful mating. Females were examined daily during the mating period. The day that the vaginal plug in a vaginal smear was observed was designated as day 0 of pregnancy. Once the vaginal plug was observed, the female and male were separated and housed individually in polycarbonate cages. A female was re-mated with a male of proven fertility within the same group if mating was not confirmed within two weeks. All rats were allowed to litter naturally (F1 generation), and rear their own offsprings until weaning.

The male rats were killed at the end of the 14-day mating period, while females that delivered were killed on day 22 after parturition. The undelivered females were killed on day 3 after the last expected parturition date. All male and female rats were subjected to a full and detailed gross necropsy. Special attention was paid to the reproductive organs. At necropsy the following organs were obtained and weighed: liver, kidney, lung, ovary, testis and epididymis.

\subsection{Sex Hormone Level}

After exposure, 4-5 mL of blood per rat was collected and stored in tubes. Collected blood samples were centrifuged at $2500 \mathrm{rpm}$ for $10 \mathrm{~min}$ at $4{ }^{\circ} \mathrm{C}$, and the serum was collected and frozen at $-80{ }^{\circ} \mathrm{C}$ for later analysis. Follicle stimulating hormone (FSH), luteinizing hormone (LH), etradiol ( $\left.\mathrm{E}_{2}\right)$ and testosterone $(\mathrm{T})$ were measured in serum by competitive enzyme-linked immunosorbent assay (ELISA) kit. All samples and standards were run in triplicate.

\subsection{Sperm Motility}

The motility parameters of sperm were analyzed with a computer-assisted sperm analysis (CASA) system (TOX IVOS, Hamilton Thorne Incorporation, Beverly, MA, USA) as follows: A quantity of $10 \mu \mathrm{L}$ of sperm diluted solution was placed on observation chambers for CASA analysis. For each male rat, four slides were analyzed. The measured motion parameters were curvilinear velocity (VCL; sum of the incremental distances moved in each frame along the sampled path and dividing by the total time for the track), average path velocity (VAP; a derived path based on an average number of points and divided by the time of the track), straight-line velocity (VSL; the straight-line distance between the start and end points of the track divided by the time of the track), beat cross frequency (BCF; turning points of the sperm head), amplitude of lateral head displacement (ALH; average deviation of the sperm head from the smoothed path), linearity (LIN; straight-line distance divided by the sum of the incremental distances along the actual path $\times 100$ ), straightness (STR; straight-line distance of the smoothed path divided by the distance along the smoothed path $\times 100$ ) and Elongation (ELON; the elongation ratio of the minor to major axis of each sperm nucleus).

\subsection{Histological Examination}

The uterus and testis were removed quickly when rats were killed and histological examination was performed following protocols described previously [57]. Briefly, tissues were fixed with 4\% paraformaldehyde, routinely processed, and embedded in paraffin and 5 micron in thickness. These 
sections were stained with hematoxylin-eosin (H\&E) for microscopic examination. All tissues taken from the control and high dose groups were examined microscopically.

\subsection{Data Analysis}

Data analysis was performed using the Statistical Analysis Software (SAS 9.1) and Microsoft Excel. The significance of differential expression between groups was assessed by $t$-test and one-way ANOVA. The quantitative data were expressed by mean $\pm \mathrm{SD}$, qualitative data were expressed in frequencies, and compared with contingency tables using $\chi^{2}$ statistics. Occurrence frequencies were characterised with a Fisher's exact test. $p<0.05$ was considered as statistically significant.

\section{Conclusions}

In summary, the findings of this study indicate that Ni NPs can be considered as a reproductive toxicant. In addition, the toxicity observed in the reproductive toxicity studies to both the female rats as well as the male were very similar, in both the severity of the effects and the concentrations at which those effects occurred. Compared with Ni MPs, the toxicity of Ni NPs was more severe in reproductive toxicity studies due to the change of particle size and surface area etc. The results of this study will be helpful to further study the long-term effects induced by Ni NPs and the scientific basis for setting standards for safety evaluation for metallic nickel nanoparticles. Further research is needed to elucidate exposure in human populations and mechanism of actions.

\section{Acknowledgments}

The authors thank the support from national important project on scientific research of China (No. 2011CB933404), the National Natural Science Foundation (No. 81172618), Preventive medicine research projects of Jiangsu Province Health Department (Y2013069) and National Training Programs of Innovation for Undergraduates (No. 1410286125).

\section{Author Contributions}

Conception and design: Lu Kong; Administrative support: Meng Tang, Yuepu Pu; Animal experiment and data collection: Lu Kong, Ting Zhang, Ke Hu, Weiqi Lu, and Chao Wei; Data analysis and drafting of manuscript: Lu Kong and Dayong Wang; Critical revisions/Supervision: Lu Kong, Meng Tang, Geyu Liang, and Yuepu Pu.

\section{Conflicts of Interest}

The authors declare no conflict of interest.

\section{References}

1. Arita, A.; Niu, J.; Qu, Q.; Zhao, N.; Ruan, Y.; Nadas, A.; Chervona, Y.; Wu, F.; Sun, H.; Hayes, R.B.; et al. Global levels of histone modifications in peripheral blood mononuclear cells of subjects with exposure to nickel. Environ. Health Perspect. 2012, 120, 198-203. 
2. Reck, B.K.; Muller, D.B.; Rostkowski, K.; Graedel T.E. Anthropogenic nickel cycle: Insights into use, trade, and recycling. Environ. Sci. Technol. 2008, 42, 3394-3400.

3. Barceloux, D.G. Nickel. J. Toxicol. Clin. Toxicol. 1999, 37, 239-258.

4. Alsop, D.; Lall, S.P.; Wood, C.M. Reproductive impacts and physiological adaptations of zebrafish to elevated dietary nickel. Comp. Biochem. Physiol. C Toxicol. Pharmacol. 2014, 165, $67-75$.

5. Eliades, T.; Pratsinis, H.; Kletsas, D.; Eliades, G.; Makou, M. Characterization and cytotoxicity of ions released from stainless steel and nickel-titanium orthodontic alloys. Am. J. Orthod. Dentofacial. Orthop. 2004, 125, 24-29.

6. Pulido, M.D.; Parrish, A.R. Metal-induced apoptosis: Mechanisms. Mutat. Res. 2003, 533, 227-241.

7. Rae, T. The toxicity of metals used in orthopaedic prostheses. An experimental study using cultured human synovial fibroblasts. J. Bone Jt. Surg. Br. 1981, 63, 435-440.

8. Ruff, C.A.; Belsito, D.V. The impact of various patient factors on contact allergy to nickel, cobalt, and chromate. J. Am. Acad. Dermatol. 2006, 55, 32-39.

9. Sunderman, F.W., Jr. A review of the metabolism and toxicology of nickel. Ann. Clin. Lab. Sci. 1977, 7, 377-398.

10. Zhao, J.; Shi, X.; Castranova, V.; Ding, M. Occupational toxicology of nickel and nickel compounds. J. Environ. Pathol. Toxicol. Oncol. 2009, 28, 177-208.

11. Kasprzak, K.S.; Sunderman, F.W., Jr.; Salnikow, K. Nickel carcinogenesis. Mutat. Res. 2003, 533, 67-97.

12. Bar-Sela, S.; Levy, M.; Westin, J.B.; Laster, R.; Richter, E.D. Medical findings in nickel-cadmium battery workers. Isr. J. Med. Sci. 1992, 28, 578-583.

13. Barton, R.T. Nickel carcinogenesis of the respiratory tract. J. Otolaryngol. 1977, 6, 412-422.

14. Chen, Y.C.; Coble, J.B.; Deziel, N.C.; Ji, B.T.; Xue, S.; Lu, W.; Stewart, P.A.; Friesen, M.C. Reliability and validity of expert assessment based on airborne and urinary measures of nickel and chromium exposure in the electroplating industry. J. Expo. Sci. Environ. Epidemiol. 2014, 24, 622-628.

15. Chiou, Y.H.; Wong, R.H.; Chao M.R.; Chen, C.Y.; Liou, S.H.; Lee, H. Nickel accumulation in lung tissues is associated with increased risk of p53 mutation in lung cancer patients. Environ. Mol. Mutagen. 2014, 55, 624-632.

16. Cragle, D.L.; Hollis, D.R.; Newport, T.H.; Shy, C.M. A retrospective cohort mortality study among workers occupationally exposed to metallic nickel powder at the Oak Ridge Gaseous Diffusion Plant. IARC Sci. Publ. 1984, 53, 57-63.

17. Doll, R.; Mathews, J.D.; Morgan, L.G. Cancers of the lung and nasal sinuses in nickel workers: A reassessment of the period of risk. Br. J. Ind. Med. 1977, 34, 102-105.

18. Hilt, B.; Leira, H.L.; Hjelde, H.; Sundstrom, S.; Brynildsen, E. Incidence and physicians' registration of assumed occupational lung cancer in Norway (in Norwegian). Tidsskr. Nor. Laegeforen. 1997, 117, 203-207.

19. Hogetveit, A.C.; Barton, R.T. Preventive health program for nickel workers. J. Occup. Med. 1976, 18, 805-808.

20. Khlifi, R.; Hamza-Chaffai, A. Head and neck cancer due to heavy metal exposure via tobacco smoking and professional exposure: A review. Toxicol. Appl. Pharmacol. 2010, 248, 71-88. 
21. Khlifi, R.; Olmedo, P.; Gil, F.; Feki-Tounsi, M.; Chakroun, A.; Rebai, A.; Hamza-Chaffai, A. Blood nickel and chromium levels in association with smoking and occupational exposure among head and neck cancer patients in Tunisia. Environ. Sci. Pollut. Res. Int. 2013, 20, 8282-8294.

22. Raithel, H.J.; Schaller, K.H.; Reith, A.; Svenes, K.B.; Valentin, H. Investigations on the quantitative determination of nickel and chromium in human lung tissue. Industrial medical, toxicological, and occupational medical expertise aspects. Int. Arch. Occup. Environ. Health 1988, 60, 55-66.

23. Roberts, R.S.; Julian, J.A.; Sweezey, D.; Muir, D.C.; Shannon, H.S.; Mastromatteo, E. A study of mortality in workers engaged in the mining, smelting, and refining of nickel. I: Methodology and mortality by major cause groups. Toxicol. Ind. Health 1989, 5, 957-974.

24. Salnikow, K.; Zhitkovich, A. Genetic and epigenetic mechanisms in metal carcinogenesis and cocarcinogenesis: Nickel, arsenic, and chromium. Chem. Res. Toxicol. 2008, 21, 28-44.

25. Sorahan, T.; Esmen, N.A. Lung cancer mortality in UK nickel-cadmium battery workers, 1947-2000. Occup. Environ. Med. 2004, 61, 108-116.

26. Yiin, J.H.; Anderson, J.L.; Daniels, R.D.; Seel, E.A.; Fleming, D.A.; Waters, K.M.; Chen, P.H. A nested case-control study of multiple myeloma risk and uranium exposure among workers at the Oak Ridge Gaseous Diffusion Plant. Radiat. Res. 2009, 171, 637-645.

27. Chromium, Nickel and Welding. Available online: http://bases.bireme.br/cgi-bin/wxislind.exe/iah/ online/?IsisScript $=$ iah/iah.xis\&src=google\&base=WHOLIS\&lang=p\&nextAction=lnk\&exprSearch $=9283212495 \&$ indexSearch $=$ ID (accessed on 14 November 2014).

28. Grimsrud, T.K.; Andersen, A. Unrecognized risks of nickel-related respiratory cancer among Canadian electrolysis workers. Scand. J. Work Environ. Health 2012, 38, 503-515.

29. Apostoli, P.; Catalani, S. Metal ions affecting reproduction and development. Met. Ions Life Sci. 2011, 8, 263-303.

30. Mohammed, E.H.; Wang, G.; Jiang, J. The effects of nickel on the reproductive ability of three different marine copepods. Ecotoxicology 2010, 19, 911-916.

31. Scott-Fordsmand, J.J.; Krogh, P.H.; Hopkin, S.P. Toxicity of nickel to a soil-dwelling springtail, Folsomia fimetaria (Collembola: Isotomidae). Ecotoxicol. Environ. Saf. 1999, 43, 57-61.

32. Sun, H.X.; Tang, W.C.; Chen, H.; Chen, W.; Zhang, M.; Liu, X.; Zhang, G.R. Food utilization and growth of cutworm Spodoptera litura Fabricius larvae exposed to nickel, and its effect on reproductive potential. Chemosphere 2013, 93, 2319-2326.

33. Forgacs, Z.; Massanyi, P.; Lukac, N.; Somosy, Z. Reproductive toxicology of nickel-review. J. Environ. Sci. Health A Tox. Hazard. Subst. Environ. Eng. 2012, 47, 1249-1260.

34. Wang, D.; Wang, Y. Nickel sulfate induces numerous defects in Caenorhabditis elegans that can also be transferred to progeny. Environ. Pollut. 2008, 151, 585-592.

35. Zhu, X.; Tian, S.; Cai, Z. Toxicity assessment of iron oxide nanoparticles in zebrafish (Danio rerio) early life stages. PLoS One 2012, 7, e46286.

36. Kovriznych, J.A.; Sotnikova, R.; Zeljenkova, D.; Rollerova, E.; Szabova, E.; Wimmerova, S. Acute toxicity of 31 different nanoparticles to zebrafish (Danio rerio) tested in adulthood and in early life stages-comparative study. Interdiscip. Toxicol. 2013, 6, 67-73.

37. Griffitt, R.J.; Luo, J.; Gao, J.; Bonzongo, J.C.; Barber, D.S. Effects of particle composition and species on toxicity of metallic nanomaterials in aquatic organisms. Environ. Toxicol. Chem. 2008, 27, 1972-1978. 
38. Magaye, R.R.; Yue, X.; Zou, B.; Shi, H.; Yu, H.; Liu, K.; Lin, X.; Xu, J.; Yang, C.; Wu, A.; et al. Acute toxicity of nickel nanoparticles in rats after intravenous injection. Int. J. Nanomed. 2014, 9 , 1393-1402.

39. Magaye, R.; Zhou, Q.; Bowman, L.; Zou, B.; Mao, G.; Xu, J.; Castranova, V.; Zhao, J.; Ding, M. Metallic nickel nanoparticles may exhibit higher carcinogenic potential than fine particles in JB6 cells. PLoS One 2014, 9, e92418.

40. Ispas, C.; Andreescu, D.; Patel, A.; Goia, D.V.; Andreescu, S.; Wallace, K.N. Toxicity and developmental defects of different sizes and shape nickel nanoparticles in zebrafish. Environ. Sci. Technol. 2009, 43, 6349-6356.

41. Taylor, U.; Barchanski, A.; Petersen, S.; Kues, W.A.; Baulain, U.; Gamrad, L.; Sajti, L.; Barcikowski, S.; Rath, D. Gold nanoparticles interfere with sperm functionality by membrane adsorption without penetration. Nanotoxicology 2014, 8, 118-127.

42. Taylor, U.; Barchanski, A.; Garrels, W.; Klein, S.; Kues, W.; Barcikowski, S.; Rath, D. Toxicity of gold nanoparticles on somatic and reproductive cells. Adv. Exp. Med. Biol. 2012, 733, 125-133.

43. Tiedemann, D.; Taylor, U.; Rehbock, C.; Jakobi, J.; Klein, S.; Kues, W.A.; Barcikowski, S.; Rath, D. Reprotoxicity of gold, silver, and gold-silver alloy nanoparticles on mammalian gametes. Analyst 2014, 139, 931-942.

44. Andersen, H.; Larsen, S.; Spliid, H.; Christensen, N.D. Multivariate statistical analysis of organ weights in toxicity studies. Toxicology 1999, 136, 67-77.

45. Kim, H.Y.; Lee, S.B.; Lim, K.T.; Kim, M.K.; Kim, J.C. subchronic inhalation toxicity study of 1,3-dichloro-2-propanol in rats. Ann. Occup. Hyg. 2007, 51, 633-643.

46. Feron, V.J.; de Groot, A.P.; Spanjers, M.T.; Til, H.P. An evaluation of the criterion "organ weight" under conditions of growth retardation. Food Cosmet. Toxicol. 1973, 11, 85-94.

47. Grandjean, P. Individual susceptibility in occupational and environmental toxicology. Toxicol. Lett. 1995, 77, 105-108.

48. Tanaka, A.; Lindor, K.; Gish, R.; Batts, K.; Shiratori, Y.; Omata, M.; Nelson, J.L.; Ansari, A.; Coppel, R.; Newsome, M.; et al. Fetal microchimerism alone does not contribute to the induction of primary biliary cirrhosis. Hepatology 1999, 30, 833-838.

49. Bilezikjian, L.M.; Blount, A.L.; Leal, A.M.; Donaldson, C.J.; Fischer, W.H.; Vale, W.W. Autocrine/paracrine regulation of pituitary function by activin, inhibin and follistatin. Mol. Cell. Endocrinol. 2004, 225, 29-36.

50. Ogasawara, H.; Ohwada, S.; Nagai, Y.; Taketa, Y.; Matsuzaki, M.; Tanaka, S.; Watanabe, K.; Aso, H.; Yamaguchi, T. Localization of leptin and leptin receptor in the bovine adenohypophysis. Domest. Anim. Endocrinol. 2008, 35, 8-15.

51. Egwurugwu, J.N.; Ifedi, C.U.; Uchefuna, R.C.; Ezeokafor, E.N.; Alagwu, E.A. Effects of zinc on male sex hormones and semen quality in rats. Niger. J. Physiol. Sci. 2013, 28, 17-22.

52. Faccio, L.; Da Silva, A.S.; Tonin, A.A.; Franca, R.T.; Gressler, L.T.; Copetti, M.M.; Oliveira, C.B.; Sangoi, M.B.; Moresco, R.N.; Bottari, N.B.; et al. Serum levels of LH, FSH, estradiol and progesterone in female rats experimentally infected by Trypanosoma evansi. Exp. Parasitol. 2013, 135, 110-115.

53. Xiong, X.; Zhong, A.; Xu, H. Effect of cyanotoxins on the hypothalamic-pituitary-gonadal axis in male adult mouse. PLoS One 2014, 9, e106585. 
54. Moore, H.D.; Akhondi, M.A. Fertilizing capacity of rat spermatozoa is correlated with decline in straight-line velocity measured by continuous computer-aided sperm analysis: Epididymal rat spermatozoa from the proximal cauda have a greater fertilizing capacity in vitro than those from the distal cauda or vas deferens. J. Androl. 1996, 17, 50-60.

55. Abbasihormozi, S.; Shahverdi, A.; Kouhkan, A.; Cheraghi, J.; Akhlaghi, A.A.; Kheimeh, A. Relationship of leptin administration with production of reactive oxygen species, sperm DNA fragmentation, sperm parameters and hormone profile in the adult rat. Arch. Gynecol. Obstet. 2013, 287, 1241-1249.

56. Yuan, C.; Wang, C.; Gao, S.Q.; Kong, T.T.; Chen, L.; Li, X.F.; Song, L.; Wang, Y.B. Effects of permethrin, cypermethrin and 3-phenoxybenzoic acid on rat sperm motility in vitro evaluated with computer-assisted sperm analysis. Toxicol. In Vitro 2010, 24, 382-386.

57. Takahashi, H.; Nakashima, S.; Takeda, S.; Ohama, E.; Ikuta, F. Topography of the serotonin neurons in the brain stem of human fetus: An immunohistochemical study. No. To. Shinkei. 1984, $36,697-708$.

(C) 2014 by the authors; licensee MDPI, Basel, Switzerland. This article is an open access article distributed under the terms and conditions of the Creative Commons Attribution license (http://creativecommons.org/licenses/by/4.0/). 